\title{
BIOTINA Y REGULACIÓN TRANSCRIPCIONAL (GÉNICA) Y EPIGENÉTICA EN LA ESPECIE HUMANA
}

\author{
Ananías García DDS*, Grégory Alfonso García MD**
}

\section{Resumen}

La biotina es una vitamina hidrosoluble del complejo B que se conoce como una coenzima para carboxilasas en la especie humana. Es evidente que está ligada en forma covalente con distintos residuos de lisina en las histonas, afectando así la estructura cromatínica, muy estudiada mediante la regulación génica y la herencia no-mendeliana transgeneracional, denominada epigenética. Esta nueva ciencia estudia las modificaciones de ADN y de las proteínas unidas a él (sobre todo histonas), que alteran la estructura de la cromatina sin modificar la secuencia nucleotídica del ADN. El objetivo de esta revisión es presentar una breve actualización sobre la biotina desde el punto de vista de regulación genética y epigenética, los roles derivados en la patogénesis de ciertas enfermedades y el entendimiento de los potenciales usos farmacológicos futuros.

Palabras clave: biotina, carboxilasa, epigenética, histona, nutrición, transcripción.

\section{BIOTIN AND TRANSCRIPTIONAL (GENETIC) AND EPIGENETIC REGULATION IN HUMANS}

\begin{abstract}
Biotin is a water-soluble B-complex vitamin known as a coenzyme for carboxylases in humans. It is evident that it covalently attaches to various lysine residues in histones, thus affecting the chromatin structure which is widely studied by means of genetic regulation and non-Mendelian transgenerational inheritance termed epigenetics. This new science, studies the modifications of DNA binding proteins (mainly histones), which alter the chromatin structure without modifying the nucleotide sequence of DNA. The objective of this review is to present a short update on biotin from the genetic and epigenetic perspective; the derived roles played in the pathogenesis of certain diseases; and the understanding of potential future pharmacological uses.
\end{abstract}

Key words: biotin, carboxylase, epigenetic, histone proteins, nutrition, transcription.

Fecha recibido: marzo 28 de 2011 - Fecha aceptado: mayo 10 de 2011

* Docente, Unidad de Morfología, Facultades de Medicina y de Terapia, Rehabilitación y Desarrollo Humano. Escuela de Medicina y Ciencias de la Salud, Universidad del Rosario. Candidato a Maestría en Morfología. UNAL, Bogotá DC, Colombia.
** Experto en Genética, Bioquímica, y Biología Celular y Molecular Humana. Experto en Farmacología y Toxicología Humana. Coordinador y Experto, Cátedra de Historia de la Medicina, Socioantropología Médica y Cultura Médica. Facultad de Medicina. Fundación Universitaria Unisánitas. Grupo de Medicina Translacional. Instituto de Investigación. Organización Sánitas Internacional. Catedrático Inmunología Clínica. Facultad de Ciencias, Pontificia Universidad Javeriana. Bogotá DC. Colombia. 


\section{Introducción}

Los hallazgos recientes acerca de la expresión genética han sido significativos y definitivos en la compresión de la biología y la patobiología humana. Sin embargo, esto sigue siendo parcial con respecto al conocimiento de la expresión y la segregación (herederabilidad) genética. El descubrimiento de que la llamada herencia genética está más allá de lo que se conoce como ácido desoxirribonucleico (ADN) en sí, puesto que está relacionado con las proteínas estructurales y de regulación de este ácido, dilucidando así un poco más los misterios que se encierran en la dinámica de lo que se conceptúa como genotipo y fenotipo.

En la actualidad es contundente la existencia de un código de la cromatina y de la remodelación de la cromatina. Cabe recordar entonces que la cromatina es esa asociación dinámica entre ADN y proteínas de diversa funcionalidad. Este es el caso de histonas, protaminas, HMG (del inglés high mobility group), proteínas de la maquinaria de reparación, recombinación y transcripción, entre otras. ${ }^{1}$

Hoy es claro que la regulación de la expresión génica se hace por la modificación postraduccional de esas proteínas asociadas. Esto implica que las proteínas luego de ser sintetizadas son modificadas por enzimas especializadas, agregando o quitando grupos radicales químicos, de lo que se encarga la epigenética, al variar la expresión de un gen o un genoma, al incidir en su nivel fenotípico, sin depender directamente del cambio de la secuencia del $\mathrm{ADN}$, sino que se segrega en forma generacional tras la división celular. ${ }^{2}$

Dentro de tales modificaciones químicas epigenéticas se encuentran reacciones covalentes de metilación, fosforilación, ubiquitinización, poli ADP-ribosilación y biotinilación. ${ }^{3.4}$ Desde el punto de vista epigenético diversos nutrientes poseen capacidad modulatoria sobre la expresión y segregación del $\mathrm{ADN}^{5}$, en especial los diferentes componentes del complejo vitamínico B. ${ }^{6}$ Es así como el estatus de metilación, poli ADP-ribosilación y biotinilación, dependen de vitaminas comoel ácido fólico y la cianocobalamina ${ }^{7}$, la niacina ${ }^{8}$ y la biotina ${ }^{9}$ respectivamente. También se ha reconocido el papel de otras vitaminas en regulación epigenética, como es sustentado con la vitamina $\mathrm{D}^{10,11}$ y los retinoides del complejo vitamínico A. ${ }^{12}$

Por todos los argumentos mencionados, es necesario brindar una aproximación al novedoso campo de la epigenética, con el fin de teorizar sobre su potencial efecto farmacéutico. A lo largo del texto nos referiremos a los genes, las proteínas, enzimas y enfermedades, mediante las nomenclaturas propuestas por OMIM (Online Mendelian Inheritance in Man) ${ }^{13}$ HUGO (Human Genome Project) ${ }^{14}$ e IUMBM (International Union of Biochemistry and Molecular Biology). ${ }^{15}$

\section{Biotina y su papel clásico: carboxilasas del metabolismo intermedio humano}

La biotina (C10H16N2O3S1), también denominada hace tiempo como coenzima $\mathrm{R}$, vitamina B7, vitamina $\mathrm{H}$ y factor $\mathrm{W}$, es una vitamina con estructura bicíclica, con química característica; uno de sus anillos es un grupo ureido y el otro es uno tetrahidrothiofeno, que contiene una cadena lateral hidrocarbonada, tipo ácido valérico (Figura 1). Funciona como acarreador del dióxido de carbono en forma de bicarbonato, encontrado en todas las formas de vida del planeta y participando en reacciones de catálisis tipo carboxilación y transcarboxilación. La contraparte vitamínica, por ser un cofactor para decarboxilación (fuera de la transaminación) es la vitamina B6 (piridoxina). ${ }^{\text {6-19 }}$

En la especie humana, al igual que en otros mamíferos, esta vitamina es un cofactor esencial, toda vez que su síntesis es por bacterias de la microbiota intestinal, de modo que como no es producida por el organismo, esta se obtiene a partir de suplencia exógena. Su papel es significativo en tanto que es estrictamente necesaria para la actividad de enzimas de tipo carboxil-transferasa, que hacen parte de las carboxilasas. Estas enzimas catalizan la incorporación de bicarbonato dentro de un blanco, en forma de un grupo carboxilo. El radical carboxilo en el inicio está unido en forma covalente al nitrógeno ureido opuesto a la cadena lateral de la biotina, para que después el grupo carboxilo sea transferido al sustrato. Se debe tener en cuenta que estas reacciones necesitan de 


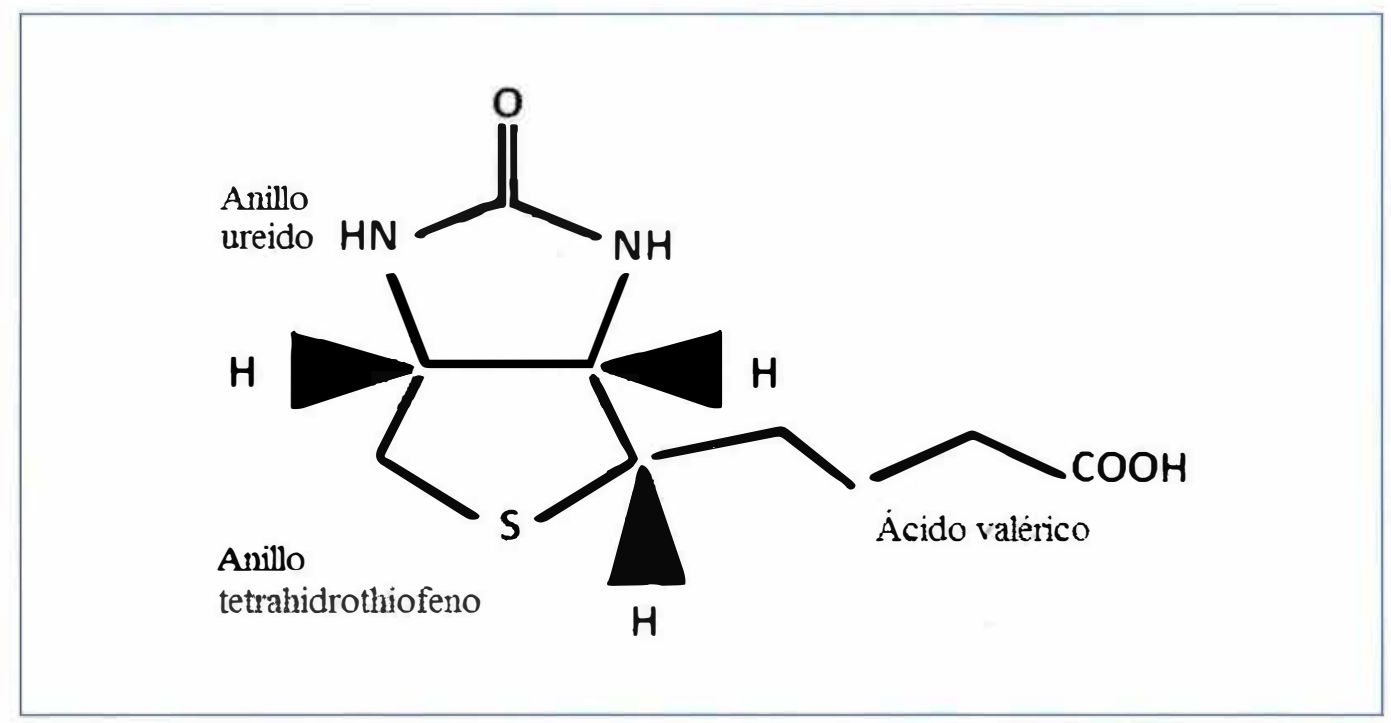

Figura I. Estructura química de la biotina, que es una orgánica compleja, en la cual se evidencia la conjunción covalente de un anillo ureido, otro tetrahidrothiofeno y una cadena lateral de ácido isovalérico.

adenosín-tri-fosfato (ATP), el cual se hidroliza para formar el intermediario biotinoil-5' AMP(B-AMP).

Al presente, se conocen cinco carboxilasas humanas, dependientes de biotina:

- Propionil-CoA-Carboxilasa(PCCA).

- Piruvato-Carboxilasa (PCC).

- Metil-cronotil-CoA-Carboxilasa (MCCC): 2 isoenzimas: $\mathrm{MCCC}$ y $\mathrm{MCCC} 2$.

- Acetil-CoA-Carboxilasa 1 (o alfa, o citosólica) (ACACAl).

- Acetil-CoA-Carboxilasa 2 (o beta, o mitocondrial) (ACACA2).

Estas enzimas son de metabolismo intermedio, puesto que participan en la biosíntesis de ácidos grasos, la degradación de aminoácidos y la gluconeogénesis. ${ }^{20-22} \mathrm{La}$ avitaminosis-hipovitaminosis olas deficiencias genéticas de estas enzimas en la especie humana demuestran la importancia de la biotina, pues en ausencia, déficit o bajo rendimiento de estas, se generan alteraciones clínicas variables de gran importancia como desórdenes neurológicos, retardo del crecimiento y anormalidades dermatológicas. ${ }^{23}$

Las proteínas catalíticas son sintetizadas (síntesis proteica) como apocarboxilasas, las cuales maduran a través de biotinilización hacia holocarboxilasas por una enzima universal denominada holocarboxilasa-sintetasa (HCS), que es condensante dependiente de ATP. En la literatura esta enzima también recibe el nombre de biotina-proteína-ligasa/biotina-holoenzima-sintetasa.

La biotinilación se efectúa sobre residuos de lisina $(\mathrm{K})$, generando el aminoácido modificado biocitina (e-Nbiotinil-L-lisina), que es reversible; la enzimaque revierte esta biotinilación, catabolizando la biocitina hacia lisina y biotina tras la proteólisis, es la biotidinasa que posee en específico una actividad biotin-peptidil-hidrolasabiotinidasa. ${ }^{16-22}$

El transporte membranal de la biotina es mediado, dependiendo del tipo de células, por dos tipos de ransportadores:

- SMVT (sodium-dependent multivitamin transporter) que corresponde en la nomenclatura HUGO a SLC5A6 [solute carrier family $5 \mathrm{~A}$ 
(sodium-dependent vitamin transporter) member 6], es el responsable a nivel intestinal de la absorción de la biotina libre, la reabsorción renal y el transporte a través de las membranas celulares en hígado y tejidos periféricos, excepto en las células sanguíneas.

- MCT1 (monocarboxylate transporter 1) que corresponde en la nomenclatura HUGO a SLC16A1 (solute carrier family 16), es el transportador predominante de biotina en las células sanguíneas. ${ }^{16-22}$

- Se interroga también la función transportadora de SLC19A3 (solute carrier family 19A-member 3), un reconocido transportador de tiamina cuyo daño monogénico produce un cuadro nosológico denominado "enfermedad de ganglios basales que responde a biotina". Una de las explicaciones que se ha dado es que este transportador es dual, es decir que funciona tanto para tiamina como para biotina. Sin embargo, este argumento se ha puesto en duda mediante experimentación de modoque no se conoce con certeza el funcionamiento del transportador. ${ }^{24}$ Véase en la Tabla 1 la genética, la enzimología y las enfermedades asociadas con estas enzimas y los transportadores mencionados.

\section{Regulación génica y biotina: un paradigma evolutivo}

El conocimiento del papel de la biotina en regulación transcripcional se conoce con certeza desde hace algunos años, pues con excepción de los mamíferos y ciertas levaduras, todos los demás organismos vivientes la

\begin{tabular}{|c|c|c|c|c|c|}
\hline $\begin{array}{c}\text { Proteína } \\
\text { (incluye otras denominaciones) } \\
\text { (15) }\end{array}$ & $\begin{array}{l}\text { Localización } \\
\text { cromosómica del gen } \\
\text { codificante }\end{array}$ & $\begin{array}{l}\text { Código } \\
\text { MIM (13) }\end{array}$ & $\begin{array}{l}\text { Clasificación } \\
\text { enzimática } \\
\quad(14)\end{array}$ & $\begin{array}{l}\text { Enfermedad } \\
\text { monogénica ligada }\end{array}$ & $\begin{array}{l}\text { Código MIM de } \\
\text { enfermedad ligada } \\
\text { (13) }\end{array}$ \\
\hline Biotinidasa & $3 p 25$ & MIM6090I9 & EC 3.5.1.12 & $\begin{array}{l}\text { Deficiencia múltiple de } \\
\text { carboxilasas de } \\
\text { ocurrencia juvenil o } \\
\text { presentación tardía }\end{array}$ & MIM253260 \\
\hline $\begin{array}{l}\text { Holocarboxilasa-sintetasa, } \\
\text { biotina-proteína-ligasa/biotina- } \\
\text { holoenzima-sintetasa }\end{array}$ & $21 q 22.1$ & MIM609018 & EC 6.3.4.10 & $\begin{array}{l}\text { Deficiencia múltiple de } \\
\text { carboxilasas de } \\
\text { ocurrencia neonatal o } \\
\text { presentación temprana }\end{array}$ & MIM253270 \\
\hline $\begin{array}{l}\text { SLC5A6 solute carrier family } \\
\text { 5A (sodium-dependent vitamin } \\
\text { transporter member 6), SMVT } \\
\text { (sodium-dependent multivitamin } \\
\text { transporter) }\end{array}$ & $2 p 23$ & MIM604024 & - & Aún no asociación & MIM245340 \\
\hline \multirow[t]{2}{*}{$\begin{array}{l}\text { SLCI6AI (solute carrier family } \\
\text { 16), MCTI (monocarboxylate } \\
\text { transporter I) }\end{array}$} & $|p| 3.2-p \mid 2$ & MIM 600682 & - & $\begin{array}{l}\text { Defecto en el } \\
\text { transportador } \\
\text { eritrocitario de lactato }\end{array}$ & MIM6I002I \\
\hline & & & - & $\begin{array}{l}\text { Hipoglicemia } \\
\text { hiperglicémica inducida } \\
\text { por ejercicio físico, de } \\
\text { patrón autosómico } \\
\text { dominante }\end{array}$ & MIM607483 \\
\hline $\begin{array}{l}\text { SLCI9A3 (solute carrier family } \\
\text { 19A member 3) }\end{array}$ & $2 q 36.3$ & MIM 606152 & - & $\begin{array}{l}\text { Enfermedad de ganglios } \\
\text { basales que responde a } \\
\text { biotina }\end{array}$ & \\
\hline
\end{tabular}


sintetizan. Este hecho permitió que desde el punto de vista evolutivo se generaran por presión selectiva positiva, sistemas genéticos y bioquímicos para sensar y transportar esta vitamina de acuerdo con las necesidades. ${ }^{25}$

Ya en los años sesenta y setenta del siglo XX, trabajos pioneros en bacterias (E. coli) del grupo de Allan Campbell en Department of Biology, University of Rochester, determinaron la existencia de un cluster (agrupamiento) de genes (Operón de clase Regulon, Bio), que codificaban un sistema enzimático y de transportadores regulados tanto por la deprivación como por el exceso de la biotina (Figura 2). Este fue el primer paso para el reconocimiento de un sensor de biotina que impactaba el perfil transcripcional de las células. ${ }^{26-30}$ Hoy existe claridad que este regulón es universal a arquebacterias, eubacterias y hay un exquisito conocimiento de cómo varía entre diversas clonoespecies de bacterias. ${ }^{31,32}$ Dado que la biotina en este punto se había identificado como una vitamina universal en el metabolismo intermedio, surgía la necesidad de demostrar cómo funcionaba la regulación transcripcional mediada por esta.

En la levadura Saccharomyces cerevisiae en 1969 se detectó la presencia de un transportador específico para biotina (VHTla Vitamin H transport) en membrana celular $^{33}$ y en el 2006 se identificó y caracterizó un regulador transcripcional específico denominado Vhrlp, el cual se une al ADN en la secuencia promotora del gen VHTl cuando se presentan bajas concentraciones extracelulares de biotina, de manera que se aumenta la probabilidad de transporte. ${ }^{34}$ En humanos, haciendo parangón a esto, los estudios de la regulación del transportador SMVT han ratificado en diversas líneas celulares que es muy dependiente de las concentraciones de esta vitamina. ${ }^{35-37}$ También se ha encontrado una regulación compleja tanto de la biosíntesis y transporte membranal como de la expresión de carboxilasas dependientes de biotina en las plantas..$^{38.39}$

El grupo de investigación David L. Vesely del departamento de Medicina de University of Arkansas for MedicalSciences, ha trabajado con intensidad en el campo de la guanilil-ciclasa (GCs) y la producción del segundo mensajero guanilil-monofosfato cíclico (GMPc) desde la década del setenta. En 1982 encontró de qué forma la biotina activa la producción de GMPc y dos años después lo hizo con análogos químicos de esta vitamina. ${ }^{40.41}$ Esto dio comienzo a la investigación acerca del funcionamiento de la biotina en cuanto a su efecto genotrópico, que es mediado por una ruta de señalamiento intracelular. Este fenómeno se explica porque el B-AMP funciona como un segundo mensajero, que en forma aún no aclarada activa la guanilil-ciclasa soluble (GCs), tras lo cual se cataliza la producción del segundo mensajero guanilil-monofosfato cíclico (GMPc) que activa la

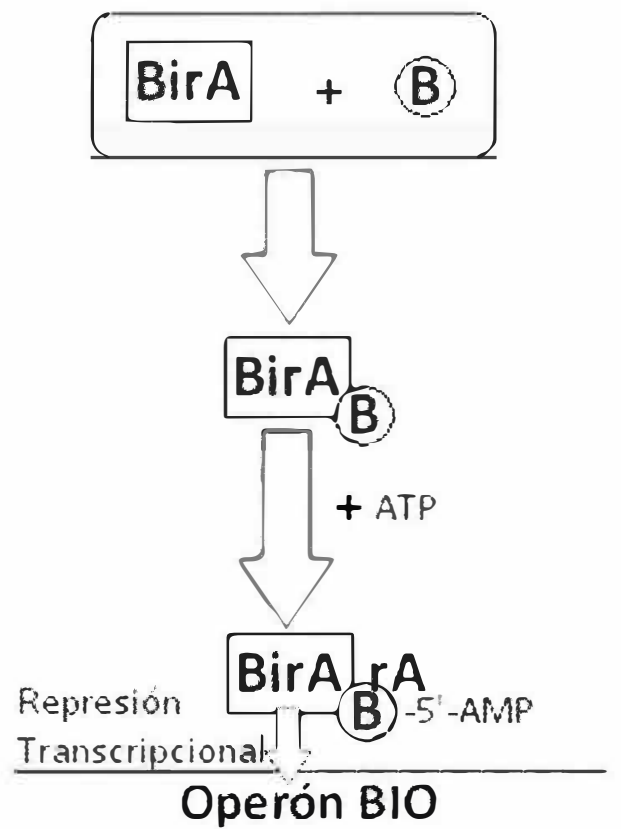

Figura 2. Regulón Bio de los procariotas, en los cuales hay agrupamientos de genes, que en conjunto tienen una función que apunta a la bioquímica de una misma ruta metabólica. Es así que el Operón Bio posee un número variable de genes dependiendo de la clonoespecie bacteriana, y estos genes son regulados de acuerdo con las concentraciones exteriores o la disponibilidad interior de biotina. Los genes codifican transportadores de biotina, enzimas dependientes de esta entre otras. El esquema muestra como una proteína denominada BirA (homóloga de HCS), al ser activada por la biotina favorece la represión transcripcional del operón. Si hay deprivación de biotina, no se efectúa la biotinilación de BirA y no se sucede la represión de genes que codifican entre otras proteínas a transportadores de membrana. 
proteína-cinasa $\mathrm{G}(\mathrm{PK}-\mathrm{G})$, la cual fosforila factores de transcripción (Figura 3). Mediante esta ruta de señalamiento intracelular, la biotina induce enzimas tales como la glucoquinasa, la fosfoenolpiruvatocarboxiquinasa, la holocarboxilasa-sintasa, el receptor de insulina y el receptor de asialoglicoproteínas. ${ }^{42-44}$

Es evidente que hay un acoplamientoentre biotinilación y fosforilación transcripcionales dependientes de biotina, generando entonces una red de regulación celular con proyección al metabolismo intermedio. ${ }^{45-47}$ Esto resultaría ser de gran trascendencia, teniendo en cuenta que existe un reporte actual de cerca de 2.000 genes distintos del genoma humano regulados diferencialmente por la biotina. $^{48}$

\section{Biotina y su nuevo rol: modificación histónica}

Existe un gran cuerpo de hallazgos científicos que confirman en definitiva cómo la biotina y las histonas

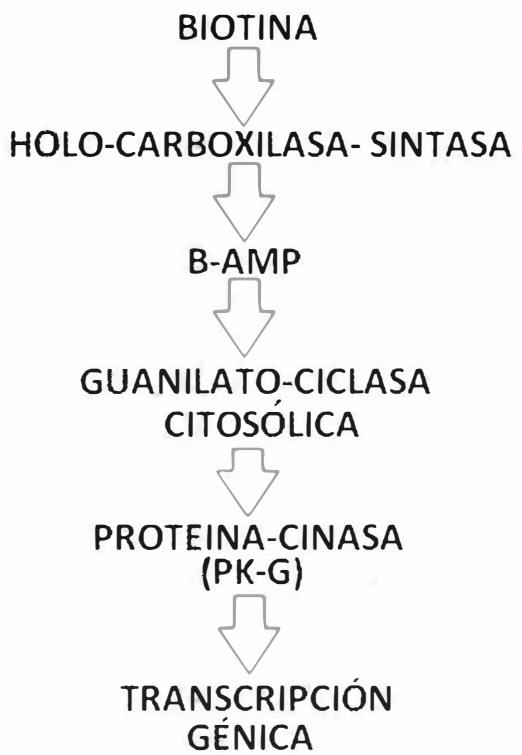

Figura 3. Biotina, GMPc y cascada de señalamiento intracelular. Esquema que muestra cómo la biotina tras ser tomada como cofactor por la HCS, se puede liberar en forma colateral como el intermediario B-AMP, el cual funciona como un segundo mensajero que activa la vía del GMPc. interactúan bioquímicamente en las células humanas. ${ }^{49}$ Desde los años ochenta ya existían reportes de la existencia deproteínas biotiniladas consideradas distintas a las carboxilasas, pero no se habían podido caracterizar. ${ }^{50,51}$ De manera paralela en la historia, es también importante recalcar que desde $1963^{52}$ y sólo hasta $1994^{53}$ se reportaba la alta concentración particular de biotina en el núcleo celular.

Pero si bien era cierta la presencia de biotina en el núcleo y la existencia de proteínas biotiniladas en él, sólo desde 1995 se detectaron con exactitud. Jeanne Hymes y colaboradores del Department of Human Genetics, Medical College of Virginia at Virginia Commonwealth University, en la búsqueda de marcadores séricos para el diagnóstico de la deficiencia de biotinidasa, fueron los primeros en detectar la biotinilación de histonas. ${ }^{54}$

Así, quedaba el interrogante de qué enzima era la encargada de tal modificación sobre las histonas y cuáles se encargaban de la reversión, es decir de la debiotinilación. Varios hallazgos han resuelto en forma parcial esta duda:

- La enzima HCS está presente en grandes cantidades en el núcleo celular. ${ }^{55}$

- La HCS probablemente participa en la biotinilación de histonas. Se ha encontrado que en fibroblastos de pacientes con deficiencia múltiple de carboxilasas por daño genético de la HCS, son deficientes en las histonas biotiniladas. ${ }^{56}$

- La biotinidasa se ha localizado en el núcleo ${ }^{57}$ y se ha demos ado que debiotinila las histonas. ${ }^{58}$ Tiene varias isoenzimas derivadas por corte y empalme alternativo del ARNm (splicing), las cuales diferencialmente se expresan en distintas localizaciones celulares. ${ }^{57}$

- Robert J Pomponio, Jeanne Hymes y colaboradores del Medical College of Virginia, en 1997 descubren que la enzima biotinidasa posee adicional actividad biotinil-transferasa, lo que facultaría a esta enzima cuando se expresa en el núcleo a biotinilar las histonas. ${ }^{59.60}$ Sin embargo, este sistema es menos eficiente que la HCS, lo cual lleva a afirmar que en 
circunstancias normales la enzima que biotinila las histonas de manera primordial es la HCS y la que debiotinila es la biotidinasa. Esta es una enzima formidable cuyo gen se logra rastrear en casi todos los phyllum genéticos evolutivos, con patrones de expresión celular y subcelular complejos, y con actividades enzimáticas múltiples que recalcan su importancia biológica. ${ }^{61}$

Shanon Healy y colaboradores de Department of Biochemistry and Molecular Biology, University of Calgary (Alberta, Canadá) encontraron además de lo planteado antes, que existe el proceso de biotinilación anenzimática de la histona H2A, basándose en circunstancias particulares en las cuales el grupo -amino de la lisina es nucleofílico y no debe estar cargado. Este proceso parece ser infrecuente, puesto que a $\mathrm{pH}$ fisiológico, este aminoácido está bastante protonado. ${ }^{62}$

Al día de hoy, se han encontrado trece sitios o posiciones aminoacídicas en las histonas, los cuales son blanco de biotinilación:

- K9, K13, K125, K127 y K129 en histona H2A. ${ }^{63}$

- K4, K9, K18 y es probable K23 en histona H3 . ${ }^{64,65}$

- K8 y K12 en H4, probable también K5 y K16 en H4. ${ }^{66,67}$

La biotinilación de K 12 en la histona H4 (H4K12bio) es un patrón característico de represión, por lo que se encuentra en la heterocromatina y en las repeticiones de ADN alfoide pericentromérico en los cromosomas eucariotas en forma predominante. Esta biotinilación coexiste con la dimetilación de los residuos K9 en la histona H3 (H3K9me2) en la heterocromatina. ${ }^{68}$

A partir de todas las consideraciones mencionadas, es concluyente afirmarque la biotina es un regulador de los patrones de remodelamiento cromatínico y de expresión epigenética de los genomas como el humano.,69.70

\section{Biotina y elementos genéticos transponibles}

La inestabilidad dinámica del genoma es la regla al momento de definir el material genético humano. Las deleciones, duplicaciones, inversiones e inserciones, son el patrón y la pauta ${ }^{1}$, al igual que son la clave para la evolución, la especiación y la individuación. ${ }^{71.72}$ Esta misma matriz dinámica de cambio es la responsable de enfermedades genéticas, que dentro de los elementos más dinámicos del genoma son los llamados "elementos transponibles, transposables o transposones", conocidos de manera popular como genes saltarines. Algunos de estos transposones se replican con base en un sistema de transcripción inversa, razón por la cual se les atribuye la nominación de "retrotransposones". Muchas de las alteraciones que logran causar los elementos transponibles más allá de ser estructurales pueden ser funcionales y se encuentran en estrecha relación con la actividad de un gen. ${ }^{1}$

Estudios en genética demuestran que la mitad del genoma humano se compone de secuencias repetitivas derivadas a partir de elementos transponibles primando los retrotransposones.' La pérdida de represión de los genes del tipo elementos transponibles y su sobreexpresión, es un hallazgo que está cobrando inusitada importancia en la génesis y en la historia natural de las enfermedades neoplásicas ${ }^{73}$, coagulopatías ${ }^{73}$ enfermedades neuropsiquiátricas ${ }^{74} \mathrm{e}$ incluso en autoinmunidad. ${ }^{75}$

La "inestabilidad genómica", es una característica de las células cancerosas, que causa daños estructurales a todo nivel en el material genético, potenciando la carcinogénesis. Esta condición de la célula neoplásica se explica en parte por la pérdida de la represión de la expresión de genes transposables.

Otro mecanismo que puede ser severo, es el hecho de que los transposones pueden funcionar como promotores génicos altemos, es decir, si caen y se integran en un gen que normalmente esta reprimido, como resultado puede favorecer su expresión anómala. ${ }^{76}$

Gran parte de la represión de los elementos transposables se logra mediante procesos epigenéticos. Dentro de esta regulación se ha encontrado que labiotinilación H4K12bio, es un mecanismo que por excelencia reprime la expresión de los retrotransposones de la clase LTR (long terminal repeat), tanto en líneas celulares murinas, células de adultos humanos y en la Drosophylla melanogaster. 
La pérdida de la biotinilación H4K12bio aumenta la frecuencia de producción de genes transponibles, lo cual posibilita el aumento de eventos de retrotransposición, que finalmente vulneran de manera estructural y/o funcional el genoma celular.

Aunque no está esclarecido el mecanismo, hay evidencia parcial de que la HCS interactúa con las histonas $\mathrm{H} 3$ y $\mathrm{H} 4$, localizando a la HCS en los retrotransposones y mediando la biotinilación de $\mathrm{H} 4$, esto dependería de la asociación inicial de HCS con regiones ricas en citosinas metiladas y a la vez parece secundar la di-metilación (H3K9me2). Estos procesos generarían represión de los elementos móviles ${ }^{77,78}$ (Figura 4).

\section{Biotina, senescencia celular y cáncer: una hipótesis}

Los telómeros son los extremos de los cromosomas lineales de las células eucariotas, los cuales se consideran como regiones de regulación que protegen frente a la inestabilidad genómica, la senescencia celular y la apoptosis por senescencia. ${ }^{\prime}$ En los mamíferos están formados por una repetición en tándem de la secuencia TTAGGG, que es una unidad por un complejo de seis proteínas especializadas, denominadas "Complejo Shelterin". El ADN telomérico, como todo el ADN nuclear, está empaquetado en histonas. ${ }^{79}$

Se ha demostrado que la modificación de histonas juega un papel regulador del largo telomérico y por lo tanto de la senescencia celular. En forma experimental, se ha encontrado que en la línea celular de fibroblastos pulmonares IMR-90 tanto normales como inmortalizados (sobreexpresando la telomerasa humana hTERT), varía la tasa de biotinilación H4K12bio en forma tal, que la senescencia celular fuera de favorecer el acortamiento telomérico, de manera colateral disminuye esta modificación postraduccional. La sobreexpresión de la telomerasa reversa tal evento, previniendo la pérdida de esta modificación postraduccional H4K12bio. Esto permite sugerir que $\mathrm{H} 4 \mathrm{~K} 12$ bio es un nuevo marcador epigenético de senescencia celular. ${ }^{80}$

La trascendencia de este hallazgo se suma también para un mejor entendimiento del proceso neoplasiogénico, puesto que en parte la inmortalización de la célula cancerosa deviene del proceso de alargamiento telomérico y esto también redundaría en la mayor biotinilación H4K12bio de las histonas de los telómeros en células neoplásicas. Sin embargo, las células cancerosas poseen un comportamiento complejo paradójico, por cuanto tienen una alta tasa de pérdida telomérica que constantemente se compensa con la sobreexpresión oncogénica del complejo telosómico, manteniendo asíalargados los telómeros y dando como resultado la inmortalización de las células. Lo que aún no está resuelto con claridad es que a pesar de esta constante activación de alargamiento telomérico, la célula cancerosa presenta una elevada inestabilidad estructural de los cromosomas.

Se ha estimado que esta paradoja se explica por cuatro factores: los rompimientos de doble hebra (DSB doublestrand breaks) en los telómeros, la presencia de sitios frágiles (lugares proclives a falla estructural) en los telómeros, la existencia de regiones subteloméricas muy sensitivas a DSB y la deficiencia de la maquinaria de reparación cromosómica. ${ }^{81,82}$

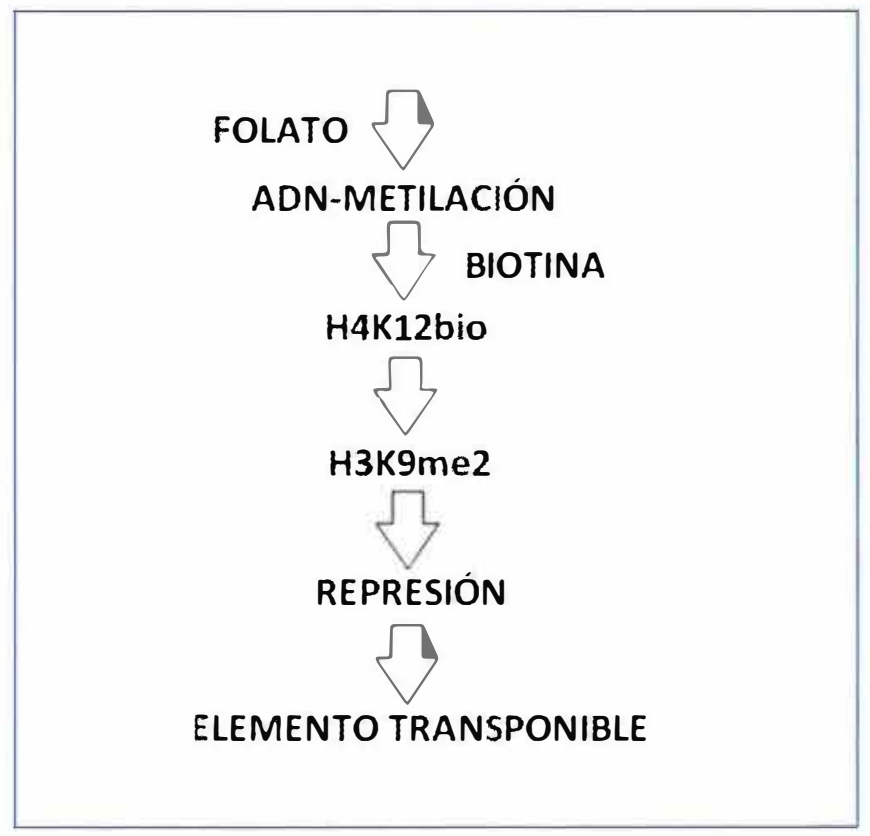

Figura 4. Biotina y represión de genes transponibles. El esquema muestra como los patrones de metilación y biotinilación coexisten como mecanismos moleculares de represión de elementos móviles génicos. Figura tomada y modificada de la referencia 78 . 


\section{Conclusiones}

Es importante, recalcar el descubrimiento de la llamativa actividad epigenética de la biotina e interrogar el protagonismo de esta vitamina en:

- Cáncer, como un potencial fármaco estabilizador genómico, disminuyendo así el avance de la desdiferenciación celular secundaria a la pérdida de la represión de elementos móviles y la desestabilización telomérica. Será fundamental aclarar qué papel juega la deficiencia subclínica de biotina en la génesis y el avance del cáncer en ciertos individuos y poblaciones. ${ }^{73,81-83}$

- Cuadros infecciosos; puesto que en forma experimental in vitro se ha encontrado que la proteína procariota ligasa BirA (homóloga de HCS), puede biotinilar histonas eucariotas. Si bien este es un hallazgo experimental, abre nuevas puertas a las hipótesis para el entendimiento de las enfermedades producidas por bacterias. ${ }^{65}$

- Hay suficiente evidencia científica de cómo labiotina regula en forma directa la expresión génica de enzimas que son dependientes de ella como cofactor (verbigracia, las carboxilasas), así como otras proteínas del metabolismo intermedio, entonces: ¿Será posible que las deficiencias subclínicas de biotina pueden jugar un papel en la génesis de la diabetes y el síndrome metabólico? ¿Es factible que la biotina tenga un carácter terapéutico y/o coadyuvante para el manejo de estas enfermedades? MF McCarty de Pantox Laboratorios (San Diego, USA) es un investigador del metabolismo intermedio, que en varios artículos científicos ha teorizado sobre el posible papel de la biotina como agente terapéutico en diabetes mellitus y síndrome metabólico. La formula que a partir de hallazgos recientes sobre el GMPc debe tratarsecomoun agente protector, trófico, antiapoptótico, que aumenta la secreción de insulina dependiente de glicemia y que incluso también eleva la insulino-sensibilidad en el tejido muscular estriado esquelético y en el hígado. ${ }^{84-88}$ Como se mencionó, la biotina utiliza una ruta de señalamiento intracelular dependiente de GMPc para la regulación génica, simulando la actividad del óxido nítrico (NO) y sus enzimas sintetizantes (NO-sintetasas). Valdría la pena interrogarse y desarrollar de manera experimental la hipótesis de si la biotina sería una novedosa aproximación farmacológica para el manejo de afecciones vasculares y metabólicas, incluyendo la enfermedad hipertensiva arterial, al inducir este segundo mensajero..$^{84-90}$

- Con estos nuevos avances en el entendimiento de la fisiología y el potencial patológico en la dinámica de la biotina, cabrá redefinir mucho mejor la fisiopatología de los signos y síntomas de los desórdenes neurológicos, del retardo del crecimiento, las anormalidades dermatológicas asociadas con deficiencia de biotina y de las enzimopatías de las carboxilasas..$^{23.91 .92}$

La biotina ha sido muy utilizada en dermatología como tratamiento formal y efectivo para el síndrome de uñas frágiles. Aún no hay claridad si la deficiencia de vitamina en sí es la causa en algunos casos o si la biotina dadas las funciones de inducción génicas discutidas en este artículo, induce la adecuada expresión de proteínas epidérmicas. ${ }^{93}$

\section{Referencias}

1. Krebs JE, Goldstein ES, Kilpatrick ST. Lewin's Genes X. 10th ed. Sudbury, MA: Jones \& Bartlett Publishers; 2009.

2. Bedregal $P$, Shand B, Santos MJ, Ventura-Juncá P. Contribution of epigenetics to understand human development. Rev Med Chil 2010;138: 366-72.

3. Chi P, Allis CD, Wang GG. Covalent histone modifications - miswritten, misinterpreted and mis-erased in human cancers. Nat Rev Cancer 2010; 10 457-69.

4. Zhu Q, Wani AA. Histone modifications: crucial elements for damage response and chromatin restoration. J Cell Physiol. 2010; 223: 283-8.

5. Oommen AM, Griffin JB, Sarath G Zempleni J. Roles for nutrients in epigenetic events. J Nutr Biochem. 2005; 16:74-7.

6. Haggarty P. B-vitamins, genotype and disease causality. Proc Nutr Soc 2007; 66: 539-47.

7. Ulrich CM, Reed MC, Nijhout HF. Modeling folate, one-carbon metabolism, and DNA methylation. Nutr Rev. 2008; 66 Suppl 1: S27-30.

8. Imai S. From heterochromatin islands to the NAD World: a hierarchical view of aging through the functions of mammalian Sirtl and systemic NAD biosynthesis. Biochim Biophys Acta. 2009; 1790: 997-1004.

9. Hassan YI, Zempleni J. Epigenetic regulation of chromatin structure and gene function by biotin. J Nutr. 2006; 136:1763-5

10. Abedin SA, Banwell CM, Colston KW, Carlberg C, Campbell MJ. Epigenetic corruption of VDR signalling in malignancy. Anticancer Res. 2006; 26:2557-66 
11. Cross HS. Extrarenal vitamin D hydroxylase expression and activity in normal and malignant cells: modification of expression by epigenetic mechanisms and dietary substances. Nutr Rev. 2007; 65:S108-12.

12. Johanning GL, Piyathilake CJ. Retinoids and epigenetic silencing in cancer. Nutr Rev. 2003; 61: 284-9.

13. OMIM [base de datos en Internet]. Baltimore: Johns Hopkins University; 1966- [citado 25 Mar 2011]. Disponible en: http://www.ncbi.nlm.nih.gov/ entrez/dispomim

14. HUGO [base de datos en Internet]. Bethesda: National Library of Medicine; 1989- [citado 25 Mar 2011]. Disponible en: http://www.hugointernational. org/index.html

15. IUMBM [base de datos en Internet]. London: International Union of Biochemistry and Molecular Biology;1977- [citado 25 Mar 2011]. Disponible en: http://www.chem.qmul.ac.uk/iupac/jcbn/index.html\#2

16. Bender DA. Nutritional biochemistry of the vitamins. 2nd. ed. Cambridge: Cambridge University Press; 2003.

17. Ball GFM. Vitamins: their role in the human body. 1st. ed. Oxford: Blackwell; 2004.

18. Zempleni J, Rucker RB, McCormick DB. Suttie JW. Handbook of vitamins. 4th. ed. Boca Raton (Florida): CRC Press-Taylor \& Francis Group; 2007

19. Zempleni J, Wijeratne SS, Hassan YI. Biotin. Biofactors. 2009; 35:36-46.

20. Berg JM, Tymoczko JL, Stryer L. Biochemistry. 6th. ed. New York: W. H. Freeman; 2006

21. Devlin TM. Textbook of biochemistry with clinical correlations. 6th. ed. New York: Wiley-Liss; 2006

22. Nelson DL, Cox MM. Lehninger'sprinciples of biochemistry. 5th. ed. New York: W. H. Freeman; 2008.

23. Scriver CR, Sly WS, Childs B, et al. The metabolic and molecular basis of inherited disease. 8th. ed. New York: McGraw-Hill Professional; 2001.

24. Subramanian VS, Marchant JS, Said HM. Biotin-responsive basal ganglia disease-linked mutations inhibit thiamine transport via hTHTR2: biotin is not a substrate for hTHTR2. Am J Physiol Cell Physiol. 2006; 291 (5):C851-9

25. Beckett $D$. Biotin sensing: universal influence of biotin status on transcription. Annu Rev Genet. 2007;41: 443-64.

26. Del Campillo-Campbell A, Kayajanian G, Campbell A, Adhya S. Biotinrequiring mutants of Escherichia coli K-12. J Bacteriol. 1967; 94:2065-6.

27. Campbell A, Del Campillo-Campbell A, Chang R. A mutant of Escherichia Coli that requires high concentrations of biotin. Proc Natl Acad Sci USA 1972; 69:676-80.

28. Cleary PP, Campbell A. Deletion and complementation analysis of biotin gene cluster of Escherichia coli. J Bacteriol. 1972; 112:830-9.

29. Cleary PP. Campbell A, Chang R. Location of promoter and operator sites in the biotin gene cluster of Escherichia coli. Proc Natl Acad Sci USA. 1972; 69:2219-23.

30. Campbell A, Chang R. Barker D, Ketner G. Biotin regulatory (bir) mutations of Escherichia coli. J Bacteriol. 1980; 142:1025-28.

31. Rodionov DA, Mironov AA, Gelfand MS. Conservation of the biotin regulon and the BirA regulatory signal in Eubacteria and Archaea. Genome Res. 2002; 12:1507-16

32. Streit WR, Entcheva P. Biotin in microbes. the genes involved in its biosynthesis, its biochemical role and perspectives for biotechnological production. Appl Microbiol Biotechnol. 2003:61:21-31
33. Rogers TO, Lichstein HC. Characterization of the biotin transport system in Saccharomyces cerevisiae. J Bacteriol. 1969; 100: 557-64.

34. Weider M, Machnik A, Klebl F, Sauer N. Vhr lp, a new transcription factor from budding yeast, regulates biotin-dependent expression of VHT1 and BIO5. J Biol Chem. 2006; 281:13513-24.

35. Pacheco-Alvarez D, Solórzano-Vargas RS, Gonzalez-Noriega A, Michalak C Zempleni J, Leon-Del-Rio A. Biotin availability regulatesexpression of the sodium-dependent multivitamin transporter and the rate of biotin uptake in HepG2 cells. Mol Genet Metab. 2005;85: 301-7.

36. Reidling JC, Said HM. Regulation of the human biotin transporter hSMVT promoter by KLF-4 andAP-2: confirmation of promoter activity in vivo. Am J Physiol Cell Physiol. 2007;292: C1305-12.

37. Reidling JC, Nabokina SM, Said HM. Molecular mechanisms involved in the adaptive regulation of human intestinal biotin uptake: a study of the hSMVT system. Am J Physiol Gastrointest Liver Physiol. 2007; 292:G275-81.

38. Nikolau BJ, Ohlrogge JB, Wurtele ES. Plant biotin-containing carboxylases Arch Biochem Biophys. 2003; 414: 211-22.

39. Roje S. Vitamin B biosynthesis in plants. Phytochemistry. 2007; 68: 1904-21.

40. Vesely DL. Biotin enhances guanulatecyclaseactivity. Science. 1982;216: 1329-30.

41. Vesely DL, Wormser HC, Abramson HN. Biotin analogs activate guanylate cyclase. Mol Cell Biochem. 1984; 60:109-14.

42. Spence JT, Koudeka AP. Effects of biotin upon the intracelullular level of cGMP and the activity of glucokinase in cultured rat hepatocytes. J Biol Chem. 1984; 259: 6393-96.

43. De La Vega LA, Stockert RJ. Regulation of the insulin and asialoglycoprotein receptors via cGMP-dependent protein kinase. Am J Physiol Cell Physiol. 2000;279: C2037-42

44. León del Río A. La vitamina biotina modifica los patrones de expresión genética en células humanas: evidencia de un sistema de regulación transcripcional multisistémica que protege el metabolismocerebral durante el ayuno. Mensaje Bioquím.. 2003; 27: 221-41

45. Rodríguez-Meléndez R, Zempleni J. Regulation of gene expression by biotin. J Nutr Biochem. 2003;14: 680-90.

46. Gravel RA, Narang MA. Molecular genetics of biotin metabolism: old vitamin, new science. J Nutr Biochem. 2005; 16:428-31.

47. León-Del-Río A. Biotin-dependent regulation of gene expression in human cells. J Nutr Biochem. 2005;16: 432-4.

48. Zempleni, J. Uptake, localization, and noncarboxylase roles of biotin. Annu. Rev. Nutr. 2005; 25, 175-96.

49. Stanley JS, Griffin JB, Zempleni J. 2001. Biotinylation of histones in human cells. Effects of cell proliferation. Eur. J. Biochem. 268:5424-29.

50. Chandler CS, Ballard FJ. Multiple biotin-containing protein in 3T3-L1 cells. Biochem J. 1986; 237: 123-30.

51. Oizumi J, Hayakawa K. Effect of plasma biotinyl-peptides on biotinidase activity. BioFactors. 1988; 2: 179-85

52. Dakshinamurti K, Mistry SP. Tissue and intracelular distribution of biotin$\mathrm{C} 14 \mathrm{OHOH}$ in rats and chicks. J Biol Chem. 1963; 238: 294-334.

53. Nakatani Y, Kitamura H, Inayama Y, Ogawa N. Pulmonary endoderma tumor resembling fetal lung: The optically clear nucleus is rich in biotin. Am J Surg Pathol. 1994; 18: 637-42. 
54. Hymes J, Fleischhauer K, Wolf B. Biotinylation of histones by human serum biotinidase: assessment of biotinyl-transferase activity in sera from normal individuals and children with biotinidase deficiency. Biochem Mol Med. 1995; 56: 76-83.

55. Solorzano-Vargas RS, Pacheco-Alvarez D, Leon-Del-Rio A. Holocarboxylase synthetase is an obligate participant in biotin-mediated regulation of its own expression and of biotin-dependent carboxylases mRNA levels in human cells. Proc Natl Acad Sci USA. 2002; 99:5325-30.

56. Narang MA, Dumas R, Ayer LM, Gravel RA. Reduced histone biotinylation in multiple carboxylase deficiency patients: A nuclear role for holocarboxylase synthetase. Hum Mol Genet. 2004; 13: 15-23.

57. Stanley C, Hymes J, Wolf B. Identification of alternatively spliced human biotinidase mRNAs and putative localization of endogenous biotinidase. Mol Genet Metab. 2004; 81: 300-12.

58. Ballard T, Wolff J, Griffin J, Stanley J, van Calcar S, Zempleni J. Biotinidase catalyzes debiotinylation of histones. Eur J Nutr. 2002: 41: 78-84.

59. Pomponio RJ, Hymes J, Reynolds TR, Meyers GA, Fleischhauer K, Buck GA. et al. Mutations in the human biotinidase gene that cause profound biotinidase deficiency in symptomatic children: molecular, biochemical, and clinical analysis. Pediat Res. 1997; 42: 840-48.

60. Hymes J, Wolf B. Human biotinidase isn't just for recycling biotin. J Nutr. 1999; 129: 485S-89S.

61. Wolf B, Jensen K. Evolutionary conservation of biotinidase: implications for the enzyme's structure and subcellular localization. Mol Genet Metab. 2005; $86: 44-50$.

62. Healy S, Heightman TD, Hohmann L, Schriemer D, Gravel RA. Nonenzymatic biotinylation of histone H2A. Protein Sci. 2009; 18: 314-28.

63. Chew YC, Camporeale G, Kothapalli N, Sarath G, Zempleni J. Lysine residues in $\mathrm{N}$ - and $\mathrm{C}$-terminal regions of human histone $\mathrm{H} 2 \mathrm{~A}$ are targets for biotinylation by biotinidase. J Nutr Biochem. 2006; 17: 225-33.

64. Kobza K, Camporeale G, Rueckert B, Kueh A, Griffin JB, Sarath G, Zempleni $\mathrm{J}$. K4, K9, and $\mathrm{K} 18$ in human histone $\mathrm{H} 3$ are targets for biotinylation by biotinidase. FEBS J. 2005;272: 4249-59.

65. Kobza K, Sarath G, Zempleni J. Prokaryotic BirA ligase biotinylates K4, K9, K18 and K23 in histone H3. BMB Rep. 2008;41:310-5.

66. Camporeale G, Shubert EE, Sarath G, Cerny R, Zempleni J. K8 and K12 are biotinylated in human histone H4. Eur J Biochem. 2004; 271:2257-63.

67. Chew YC, Raza AS, Sarath G, Zempleni J. Biotinylation of K8 and K12 co-occurs with acetylation and mono-methylation in human histone $\mathrm{H} 4$. FASEB J. 2006; 20:A610.

68. Camporeale G, Oommen AM, Griffin JB, Sarath G, Zempleni J. K12biotinylated histone $\mathrm{H} 4$ marks heterochromatin in human lymphoblastoma cells. J Nutr Biochem. 2007;18:760-8.

69. Hassan YI, Zempleni J. A novel, enigmatic histone modification: biotinylation of histones by holocarboxylase synthetase. Nutr Rev. 2008; 66:721-5.

70. Zempleni J, Chew YC, Hassan YI, Wijeratne SS. Epigenetic regulation of chromatin structure and gene function by biotin: are biotin requirements being met? Nutr Rev. 2008 Aug; 66 Suppl 1:S46-8.

71. Bourque G. Transposable elements in gene regulation and in the evolution of vertebrate genomes. Curr Opin Genet Dev. 2009; 19:607-12.

72. Cordaux R, Batzer MA. The impact of retrotransposons on human genome evolution. Nat Rev Genet. 2009;10: 691-703.
73. Schneider AM, Duffield AS, Symer DE, Burns KH. Roles of retrotransposons in benign and malignant hematologic disease. Cellscience. 2009;6:121145 .

74. Buretiæ-Tomljanoviæ A, Tomljanoviæ D. Human genome variation in health and in neuropsychiatric disorders. Psychiatr Danub. 2009;21: 562-9.

75. Perron $\mathrm{H}, \mathrm{Lang} \mathrm{A}$. The human endogenous retrovirus link between genes and environment in multiple sclerosis and in multifactorial diseases associating neuroinflammation. Clin Rev Allergy Immunol. 2010;39: 51-61.

76. Cohen CJ, Lock WM, Mager DL. Endogenous retroviral LTRs as promoters for human genes: a critical assessment. Gene. 2009;448:105-14.

77. Chew YC, West JT, Kratzer SJ, Ilvarsonn AM, Eissenberg JC, Dave BJ. et al. Biotinylation of histones represses transposable elements in human and mouse cells and cell lines and in Drosophila melanogaster. J Nutr. 2008;138: 2316-22.

78. Zempleni J, Chew YC, Bao B, Pestinger V, Wijeratne SS. Repression of transposable elements by histone biotinylation. J Nutr. 2009;139: 2389-92.

79. Martínez P, Blasco MA. Role of shelterin in cancer and aging. Aging Cell. 2010 Jun 21.

80. Wijeratne SS, Camporeale G, Zempleni J. K12-biotinylated histone $\mathrm{H} 4$ is enriched in telomeric repeats from human lung IMR-90 fibroblasts. J Nutr Biochem. 2010; 21:310-6.

81. Murnane JP. Telomere loss as a mechanism for chromosome instability in human cancer. Cancer Res. 2010;70: 4255-9.

82. O'Sullivan RJ, Karlseder J. Telomeres: protecting chromosomes against genome instability. Nat Rev Mol Cell Biol. 2010; 11:171-81.

83. Young VR, Newberne PM. Vitamins and cancer prevention: issues and dilemmas. Cancer. 1981; 47 (5 Suppl):1226-40.

84. McCarty MF. High-dose biotin, an inducer of glucokinase expression, may synergize with chromium picolinate to enable a definitive nutritional therapy for type II diabetes. Med Hypotheses. 1999;52: 401-6.

85. McCarty MF. High-dose biotin may down-regulate hepatic expression of acute phase reactants by mimicking the physiological role of nitric oxide. Med Hypotheses. 2003;61: 417-8.

86. McCarty MF. Nutraceutical resources for diabetes prevention - an update. Med Hypotheses. 2005; 64:151-8.

87. McCarty MF. cGMP may have trophic effects on beta cell function comparable to those of cAMP, implying a role for high-dose biotin in prevention/ treatment of diabetes. Med Hypotheses. 2006;66: 323-8.

88. McCarty MF. Exenatide and biotin in conjunction with a protein-sparing fast for normalization of beta cell function in type 2 diabetics. Med Hypotheses. 2007;69: 928-32

89. García GA, Clavijo Grimaldi D, Mejía OR, García Cardona A, Vittorino M, Casadiego CA. Escenciales en Biomedicina (Biología, Patobiología y Bioclínica) Humana de las NOSS (Óxido Nítrico-Sintetasas). Rev CES Med. 2007; 21: 61-82.

90. García GA, Mejía OR, García Cardona A, Gaitán AA. Esenciales en biología, patobiología y bioclínica del óxido nítrico. Med UIS. 2009;22: 41-54.

91. Pacheco-Alvarez D, Solórzano-Vargas RS, Del Río AL. Biotin in metabolism and its relationship to human disease. Arch Med Res 2002;33: 439-47.

92. Zempleni J, Hassan YI, Wijeratne SS. Biotin and biotinidase deficiency. Expert Rev Endocrinol Metab. 2008;3: 715-24.

93. Scheinfeld N, Dahdah MJ, Scher R. Vitamins and minerals: their role in nail health and disease. J Drugs Dermatol. 2007; 6: 782-7. 